\title{
CONVERSANDO COM JOVELINAS, IVONES E BETHS: SAÚDE E ENVELHECIMENTO NO MUNDO DO SAMBA
}

\author{
HABLANDO CON JOVELINAS, IVONES Y BETHS: \\ SALUD $\Upsilon$ ENVEJECIMIENTO EN EL MUNDO \\ DE LA SAMBA BRASILEÑA
}
TALKING TO JOVELINAS, IVONES AND BETHS: HEALTH AND AGING IN SAMBA'S WORLD

\author{
Adriana Miranda de Castro ${ }^{1}$, Claúdia Bonan ${ }^{1}$ e Paula Gaudenzi ${ }^{1}$ \\ ${ }^{1}$ Fundação Oswaldo Cruz, Rio de Janeiro/RJ, Brasil
}

\begin{abstract}
RESUMO: Partindo das análises foucaultianas quanto à relação de imanência em que se constituem capitalismo, biopoder e medicalização da vida, analisamos as modulações neoliberais das relações de poder-saber e a produção de um sujeito empresário de si, que trabalha por um desempenho ótimo em todos os campos da existência. Interessa-nos problematizar as repercussões dessa lógica econômica no campo da saúde na medida em que engendra subjetividades previdentes, que devem seguir as prescrições do aparato biomedicina, epidemiologia e promoção da saúde para assegurar longevidade e vitalidade, assim como seu investimento na construção da velhice como um Universal, cuja experiência oscila entre fragilidade/ envelhecimento ativo. Nossas reflexões se fazem numa incursão etnográfica à Ala dos Cabelos Brancos, velha guarda do GRES Império Serrano, onde cartografamos os modos de produção de si e de realidade que acionam como universo de referência o mundo do samba e estabelecem sentidos singulares para saúde e velhice.
\end{abstract}

PALAVRAS-CHAVE: Biopoder; Medicalização; Envelhecimento; Samba.

RESUMEN: A partir de los análisis foucaultianos sobre la relación de inmanencia en la que se constituyen el capitalismo, el biopoder y la medicalización de la vida, analizamos las modulaciones neoliberales de las relaciones poder-conocimiento y la producción de un sujeto emprendedor que trabaja por un óptimo desempeño en todos campos de existencia. Nos interesa problematizar las repercusiones de esta lógica económica en el campo de la salud en tanto engendran subjetividades preventivas, que deben seguir las prescripciones del aparato de biomedicina, epidemiología y promoción de la salud para asegurar la longevidad y vitalidad, así como su inversión en la construcción de la vejez como Universal, cuya experiencia oscila entre fragilidad/envejecimiento activo. Nuestras reflexiones se realizan en una incursión etnográfica en el "Ala de Cabello Blanco", la vieja guardia de GRES Imperio Serrano, donde mapeamos los modos de producción del yo y la realidad que disparan el mundo de la samba como universo de referencia y establecen sus significados únicos acerca de la salud y la vejez.

PALABRAS CLAVES: Biopoder; Medicalización; Envejecimiento; Samba.

ABSTRACT: Starting from the Foucaultian analyses regarding the immanence relation in which capitalism, biopower and medicalization of life are constituted, we analyse the neoliberal modulations of power-knowledge relations and the production of a self-entrepreneur's subject, who works for a great performance on all fields of existence. We are interested in problematizing the repercussions of this economic logic on the health field as it engenders foresightful subjectivities. In this context, these must follow the prescriptions of the biomedicine, epidemiology and health promotion apparatus to ensure longevity and vitality, as well as its investment in the construction of old age as a Universal, whose experience fluctuates between frailty/active aging. Our reflections are made in an ethnographic foray into the "Ala dos Cabelos Brancos", the old guard of GRES Imperio Serrano, where we map the modes of production of self and reality that set the samba world as a reference universe and establish unique meanings for health and old age. KEYWORDS: Biopower; Medicalization; Aging; Samba. 


\section{Introdução}

Nos últimos 40 anos, o envelhecimento da população mundial tem sido objeto de comemoração e preocupação. Por um lado, ele ratificaria a efetividade de uma série de tecnologias de gestão da vida, notadamente aquelas próprias aos processos de medicalização. Por outro, apresentaria outros impasses como a sustentabilidade econômica das sociedades na medida em que se alteram as relações entre expectativa de vida e taxa de fecundidade e/ou população economicamente ativa e aposentados (Neilson, 2019).

As leituras hegemônicas sobre o envelhecimento populacional repercutem nas estratégias de individualização e totalização que incidem sobre a velhice, buscando naturalizar e homogeneizar o modo como os sujeitos em diferentes cenários socioculturais, políticos e econômicos irão experimentá-la e significá-la. Nessa direção, discursos e práticas priorizam uma compreensão da velhice como um fato "biologicamente auto-evidente" (Neilson, 2019, p. 31 ), que implicará fragilidade ou não conforme o autocuidado individual.

No plano de imanência (Guattari, 1992) em que se articulam a lógica capitalística, o biopoder e a medicalização da vida, os processos de produção de si e de realidade são marcados por estratégias de equalização e captura a fim de que se produzam sujeitos presos a padrões identitários e a uma compreensão dicotômica da existência. Nessa direção, em suas modulações liberal e neoliberal viu-se emergir a figura de um "empresário de si" (Dardot \& Laval, 2016), sujeito que controla a si mesmo para afastar-se do lugar de "perdedor" e conquistar a "vitória" em todos os campos da existência.

No âmbito da saúde, o sujeito-empresário vencerá caso se mantenha saudável, jovial, ativo e produtivo. O "envelhecimento ativo" (OMS/OPAS, 2005) será o prêmio de um modo de viver previdente, que evite os riscos e faça escolhas saudáveis, segundo as prescrições do aparato complexo em que se articulam biomedicina, epidemiologia e promoção da saúde. No entanto, se falhar, se transgredir, o sujeito-empresário terá uma velhice vulnerável e frágil, se constituindo num "problema social”, num peso econômico.

Nesse sentido, a velhice é produzida como um “universal” (Guattari, 1992), invisibilizando as desigualdades sociais que atravessam e conformam as experiências de envelhecer e o fato de que os diferentes grupos sociais podem criar e veicular sistemas de subjetivação referidos a outros "universos de referência" (Guattari, 1992).

No presente artigo, interessa-nos problematizar os processos de produção de subjetividades e de verdade em que se articulam a medicalização da vida e a produção social da velhice. Analisaremos a construção do modo empresário de si engendrado pelas relações de saber-poder na lógica neoliberal e sua articulação à imagem do envelhecimento ativo/terceira idade como resultado do desempenho ótimo dos sujeitos, assim como realizaremos uma incursão etnográfica junto à "Ala dos Cabelos Brancos", do Grêmio Recreativo Escola de Samba Império Serrano a fim de cartografar os modos de produção de si e de mundo que se articulam ao universo de referência do mundo do samba e seus efeitos na construção da velhice como um "território existencial” (Guattari, 1992).

A Ala dos Cabelos Brancos, fundada em 1957, reúne homens e mulheres sob a designação de velha guarda, demarcando-se como espaço coletivo relativo aos mais velhos da escola de samba, àqueles que guardam a sua tradição. Portanto, constituiu-se como locus privilegiado para que pudéssemos refletir se é possível criar outros sentidos para saúde e velhice, que tensionem, modifiquem e/ou subvertam a lógica hegemônica, sustentando "processos de singularização” (Guattari, 1992) da existência. 


\section{Biopoder e medicalização: um sujeito-empresário-saudável}

Nas reflexões foucaultianas dos anos de 1970, o processo histórico em que a vida se tornou objeto de investimento das relações de saber-poder é colocado em análise. Os estudos ocupam-se das tecnologias e efeitos do biopoder na inclusão de todos e de cada um num sistema político-econômico, que se interessa por sujeitar corpos e controlar populações (Foucault, 1988).

Dentre os regimes de produção de verdade organizados para garantir o funcionamento do biopoder no socius, os processos de medicalização desempenham um papel importante, na medida em que afirmam um propósito "inquestionável”: a defesa da vida. Propósito que, inegavelmente, tem sido alcançado - embora, não para todos -, se considerarmos, por exemplo, o aumento na expectativa de vida.

Ao longo do século XX, no plano de imanência (Guattari, 1992) em que se constituem as tecnologias de governo da vida, o conceito de risco emergiu com importância crescente nas modulações liberais e neoliberais das relações de saber-poder (Caponi, 2016). Sua relevância vincula-se, em parte, à capacidade de se inscrever em diferentes domínios da vida, remetendo a uma economia de ganhos e perdas e, num sentido mais estrito, à probabilidade de um efeito desfavorável. Concomitantemente, silencia as contradições do hoje e promete um futuro dependente da construção racional das escolhas “adequadas" (Castiel, Guilam, \& Ferreira, 2010).

No âmbito da medicalização, a categoria risco articula os saberes produzidos pela biomedicina, a epidemiologia e a promoção da saúde. A composição desses três modos de apreender e intervir na vida constitui um aparato complexo, que amplia as "formas de governar as pessoas, individual e coletivamente" (Zorzanelli \& Cruz, 2018, p. 726), posto que institui tecnologias capazes de predizer um futuro "saudável” ou não. Nesse sentido, os saberes vinculados à produção de saúde se espraiam no socius, dizendo daquilo que precisamos fazer para "fugir" da incapacidade, da doença e/ou da morte.

Opera-se a produção de um valor transcendente - a saúde como "completo bem-estar biopsicossocial” (OMS, 1946) -, que engendra subjetividades marcadas pelo sentimento de falha e pela busca incessante de um ideal. Estabelecendo relações totalizantes e binárias, tais como: "saudável/não saudável”, "comportamentos de risco/comportamentos de proteção”, a lógica capitalística trabalha pela padronização dos modos de produção de si e de realidade, a que vincula um lucrativo mercado consumidor.

Nessa direção, tecnologias digitais e biotecnologias são incorporadas ao mercado da saúde, garantindo ao consumidor informação sobre aquilo que ele nem sabe que existe em seu corpo, como, por exemplo, um gene vinculado à probabilidade de uma doença. Simultaneamente, meios de comunicação e internet disponibilizam toda sorte de informações (des)necessárias para um suposto aprimoramento dos corpos e dos estilos de vida.

Assim, as relações de saber-poder engendram determinados esquemas de pensar/agir como "universais" (Guattari, 1992), sob pretensa neutralidade científica e argumentando que seu único interesse é proteger a vida. Articulando tecnologias de dominação às tecnologias de si, se investe na colonização das forças desejantes e na incitação de uma atitude de pretensa liberdade. O sujeito torna-se "empresário de si” (Dardot \& Laval, 2016), um operador das formas de controle focado em responder às exigências de desempenho.

Ao sujeito-empresário cabe guiar a própria vida segundo uma lógica contábil, mantendo uma atitude empreendedora e autovigilante para obtenção de sucesso. Nesse processo, 
a saúde constitui um projeto gerencial, cujo êxito é medido por longevidade e vitalidade. Customizam-se práticas e produtos relativos ao mercado da saúde de forma que os diversos estratos populacionais sejam alcançados pela lógica do consumo do "saudável" (Clarke, Mano, Fosket, Fishman, \& Shim, 2010).

Tal movimento repercute em vários campos da vida e incide nos "territórios existenciais" (Guattari, 1992) a fim de equalizar todas as possibilidades de alteridade, fixando as subjetividades num enquadre compatível à lógica hegemônica. Assim, a velhice é produzida como uma identidade universal, em que o projeto do sujeito-empresário-saudável é escapar da fragilidade/vulnerabilidade, seguindo as prescrições que acenam com um "envelhecimento ativo" (OMS/OPAS, 2005).

\section{Velhice: movimentos de individualização/totalização}

Na modernidade, por meio de operações de individualização/totalização, instituiu-se a ideia de curso de vida. Sucessão unidirecional, evolutiva e universal de estágios perfeitamente definidos quanto àquilo que o corpo é e como funciona e quanto aos afetos e comportamentos adequados/esperados ou não. O curso de vida naturaliza-se tomando como suporte a idade cronológica (Debert, 1997).

Tal "determinismo bioideológico" (Motta, 2002, p. 38), alinhado aos interesses do modelo produtivo, das instituições de educação e saúde, do mercado de consumo e das políticas públicas de ordenamento do socius, produz a velhice como "estágio problema". $\mathrm{O}$ velho existe marcado por limitações, improdutividade e iminência da morte.

Transfeita preocupação social, política e econômica, a velhice é objetivada por diferentes regimes de verdade, que pretendem delinear e defender interesses, necessidades e a própria existência dos chamados "idosos". Correlata à invenção dessa categoria é a emergência da geriatria/gerontologia como campo do saber que falará "a” verdade do envelhecimento.

Os efeitos da circulação dos discursos da geriatria/gerontologia são complexos e, por vezes, contraditórios. De um lado, se constrói uma perspectiva homogênea da velhice como tempo de vulnerabilidade e fragilidade, exigindo proteção e cuidado vinculados à seguridade social e fundamentados na normalização oriunda dos saberes médicos. Por outro lado, se investe na desconstrução dos estereótipos negativos vinculados a ser velho, realçando seus ganhos e encorajando todos a trabalhar por um "envelhecimento ativo".

Nesse contexto, cria-se a "terceira idade", uma etapa do curso de vida entre o adulto e o velho em que a existência seria alegre, cheia de autorrealização e lazer, pois já não haveria o "peso" dos compromissos familiares e profissionais. Esse momento "mágico", no entanto, só estaria disponível àqueles que vivam conforme as normas de cuidado com a saúde, garantidoras da manutenção da capacidade funcional dos corpos (Debert, 2013; Motta, 2002). Assim, saberes e práticas da gerontologia/geriatria se espraiam por todo o curso de vida, universalizando como imagem objetivo o "envelhecimento ativo/terceira idade".

Entretanto, frente ao desmonte das políticas de garantia de direitos empreendido pela racionalidade neoliberal, as condições estruturais para ter "qualidade de vida" na velhice são mínimas e, até mesmo, impeditivas para grande parte da população. Desse modo, fazer da velhice um "problema de consumidores falhos" (Debert, 2013, p. 30) ou empresários incapazes de assegurar uma "longevidade produtiva" (Rougemont, 2016, p. 192) é problemático. 
Em meio às ambiguidades na produção da velhice, há consenso de que todos experimentam biologicamente os efeitos do tempo, mas que "as formas pelas quais envelhecemos diferem muito - por gênero, raça e classe mais obviamente, mas também por experiências históricas que afetam as coortes geracionais e as contingências das biografias individuais" (Neilson, 2019, p. 31 ).

Nesse sentido, há algo que escapa à totalização da experiência da velhice e que pode operar "processos de singularização" (Guattari, 1992). Trata-se, pois, de compreender o significante "velhice" como expressão que remete a territórios existenciais, que podem ser mais ou menos ancorados na lógica hegemônica e/ou abertos à mudança, mas que são sempre polifônicos, situados e provisórios (Guattari, 1992; Romagnoli, 2009; Tedesco, 2015).

Considerando as operações das relações de saber/poder na racionalidade liberal e neoliberal e seus efeitos na produção de subjetividades, interessa-nos pensar: é possível criar outros modos de viver? Há linhas de força a serem acionadas na produção de si e de realidade que ressignifiquem saúde e envelhecimento?

\section{Ala dos Cabelos Brancos: chegando ao mundo do samba}

Compreendendo que territórios existenciais podem emergir de múltiplos "universos de referência" (Guattari, 1992) e interessadas em fazer falar àqueles que se situem às margens do status quo, elegemos trabalhar com as velhices articuladas ao mundo do samba.

No Brasil, quando surgiu, o termo samba vinculava-se a uma forma de dançar nas festas dos povoados nas zonas rurais, a qual remetia a modos de se relacionar com o corpo diferentes do hegemônico, pois se associavam aos corpos negros, sua cultura e sua forma resistir à escravização. Dançava-se em roda, ocupando coletivamente o espaço do terreiro com grande liberdade corporal, marcada pela expansão dos gestos e pelo toque mútuo (Silva, 2013; Sodré, 2019).

Corpo, dança e terreiro se articulavam, produzindo um território ético-estéticopolítico potente na preservação e transmissão da memória da estrutura social, da cultura e religiosidade dos africanos escravizados no país. Nessa direção, as festas eram estratégias "de resistência ao imperativo social (escravagista) de redução do corpo negro a uma máquina produtiva e como uma afirmação de continuidade do universo cultural africano" (Sodré, 1998, p. 12). O samba emerge, pois, marcado pela cosmogonia dos vários povos africanos escravizados e as (re)composições que ela sofreu e fez aqui.

Tal cosmogonia se caracteriza pela integração do sujeito à ordem cósmica, na qual sagrado e profano não se opõem radicalmente, e ocupar um espaço tem grande importância. Ao povo negro escravizado coube reinventar os espaços de produção de si e de realidade, tendo como suporte uma territorialidade singular uma vez que construída em diáspora. Nesse sentido, corpo, terreiro e casa falavam de espaços em que conhecimentos se materializavam, transformavam e expandiam em contínua relação com outras espacialidades. Dessa maneira, o espaço é tratado como algo plástico, que existe num movimento de (re)fazer-se (Sodré, 2019).

Os movimentos de (re)fazer-se não aconteceriam sem uma rede de solidariedade organizada, em especial, pela liderança das mulheres, agentes fundamentais na sustentação dos espaços vinculados à negritude. Longe dos parâmetros de feminilidade hegemônicos e marcadas pelas violências da escravidão, trabalho compulsório e circulação nos espaços 
públicos, são elas que arcarão com a subsistência de corpos, terreiros e laços de parentalidade negros (Davis, 2016; Werneck, 2007). É sob a liderança e as bençãos de mulheres negras, das "tias baianas" (Velloso, 1990), que se agenciam comunidades negras potentes em resistir ao apagamento de seus modos de viver, criando os espaços onde emergirá o samba urbano carioca.

Compreendemos que o mundo do samba faz circular enunciados e práticas relacionados à história social e à religiosidade negras, remetendo a movimentos não hegemônicos numa sociedade racista (Lopes \& Simas, 2017). Tais enunciados e práticas se expressam, ainda hoje, pela importância das festas, pelo acionamento do humor e do deboche ao narrar o cotidiano e pela centralidade dos espaços e experiências coletivas, como: o terreiro, a roda de samba e a escola de samba.

Considerando a centralidade do coletivo nos modos de viver vinculados ao mundo do samba, entendemos que esses seriam os melhores cenários para nossas análises. Portanto, buscamos um espaço coletivo que mantivesse uma relação orgânica com o mundo do samba e, simultaneamente, pudesse apontar outros modos de envelhecer, chegando à Ala dos Cabelos Brancos.

A Ala dos Cabelos Brancos vincula-se ao Grêmio Recreativo Escola de Samba Império Serrano, fundado em 1947 no Morro da Serrinha em Madureira, subúrbio do Rio de Janeiro. A fundação da Império Serrano aconteceu na casa de Tia Eulália, remetendo às histórias sobre a importância das matriarcas negras no surgimento do samba, e com forte presença de trabalhadores portuários. Fundada em 1957, a Ala se tornou responsável por preservar as tradições imperianas em 1965 (Valença \& Valença, 2017).

Chegamos aos Cabelos Brancos por Alcione ${ }^{1}$, que passou a integrá-los em 2014. Por suas estórias descobrimos que o Império Serrano possuía duas alas com título de Velha Guarda, o que não acontece noutras escolas de samba. Estranhamos e quisemos saber mais sobre como ela entrara numa "velha guarda" não se enquadrando no perfil comumente a ela associado.

No senso comum a imagem da velha guarda se vincula à sua clássica definição no mundo do samba: "conjunto dos sambistas veteranos, mais antigos e respeitados ... defensores da tradição" (Lopes \& Simas, 2017, p. 295). Porém, conforme indica Leila Blass (2011), é possível utilizar o termo para designar ainda: uma ala que siga o critério etário - ter acima de 50 anos, em escolas de samba com menos tempo de existência, e a chamada "velha guarda show", que reúne pastoras e compositores em apresentações para divulgar a marca e os sambas da escola.

Embora goste de samba e tenha um irmão que integrou baterias de escola de samba, Alcione não se enquadra em nenhum dos perfis. Mais tarde veríamos que os Cabelos Brancos também não se enquadram totalmente às descrições consagradas de velha guarda.

O rito de entrada na Ala não implicava ter uma vida inteira ligada à história da escola, embora nela exista quem a tenha, nem ser considerado velho pelo padrão etário legal. Trata-se de ser apresentado por um membro da Ala, ter mais de 45 anos, "conversar" com a diretoria, ter autorização do presidente, passar a frequentar com assiduidade as reuniões semanais, contribuir com a mensalidade e a "caixinha" das festas e providenciar um enxoval de roupas e sapatos para participar dos eventos. Assim, Alcione chegou à mesma.

Se há um rito para se tornar um Cabelo Branco, então faz sentido que a construção de nossa incursão etnográfica também fosse ritualizada. Nosso primeiro contato foi com Leci, membro da diretoria da Ala. Enviamos uma mensagem de áudio por aplicativo, 
nos apresentando, explicando o tema e os objetivos da pesquisa e perguntando se poderíamos nos encontrar. A primeira reação foi indicar que deveríamos frequentar as escolas de samba, pois cada uma "tem seu modo de viver ... porque aí ... fazia uma globalização de um todo". Apesar da concepção de Leci sobre o que seria "um bom trabalho" ou, talvez, por causa dela, convidou-nos a participar da festa da Velha Guarda do GRES Paraíso do Tuiuti, que seria no domingo seguinte.

As velhas guardas integram a Associação das Velhas Guardas das Escolas de Samba do Rio de Janeiro, que coordena ao longo do ano o "Encontro das Bandeiras". Todo domingo à tarde uma velha guarda anfitriã oferece um almoço para as demais, normalmente na quadra de sua escola de samba. Durante o almoço, todas as velhas guardas desfilam com suas bandeiras e roupas de festa ao som do samba que representa cada uma. Depois, assistem e/ou dançam num show curto, que pode ou não ser de samba.

Naquele domingo, descobrimos que os Cabelos Brancos adquiriram o status de guardiões da tradição do Império Serrano por serem uma das alas mais antigas em funcionamento na escola. Legitimar-se como uma velha guarda significou que o presidente da Ala obteve autorização do presidente da escola para filiar-se à Associação. Nesse sentido, foi a história da Ala e não de seus membros individualmente que a fez uma "velha guarda". Por outro lado, pareceu-nos haver também uma correlação com o próprio envelhecimento de seus membros e a construção de uma saída para, frente à aceleração dos desfiles, seguir participando da festa. Como disse Jovelina: "Pra poder no dia do desfile, eu aguentar [é] passar no ritmo do Cabelo Branco. Eu não vou aguentar passar no ritmo de uma ala".

Após o encontro inicial, convidaram-nos para a reunião semanal dos Cabelos Brancos, que acontece nas noites de terça-feira no Irajá Atlético Clube. As reuniões ocorrem, na verdade, em duas etapas. Uma primeira no salão social do Clube, em que são dispostas uma mesa de diretoria, mesas auxiliares de tesouraria e lista de presença e cadeiras em formato de assembleia, nas quais homens e mulheres se sentam separadamente. A etapa seguinte é no "escritório", um bar próximo, onde numa mesa em "L" se sentarão separados homens e mulheres para beber cerveja, petiscar e conversar até por volta das $23 \mathrm{~h}$.

Nossa pesquisa também envolveu duas etapas. Entre julho/2017 e outubro/2018 realizamos observação participante nos três principais cenários de encontro da Ala dos Cabelos Brancos: as festas de Velha Guarda, as reuniões no Irajá Atlético Clube e o "escritório".

Numa segunda etapa, entre outubro/2018 e março/2019, entrevistamos oito mulheres que integram os Cabelos Brancos. Considerando que o envelhecimento no Brasil é marcado pela "feminização" (Camarano, 2006) e pensando nos discursos que associam, tradicionalmente, as mulheres idosas do mundo do samba à imagem das “tias”, elegemos analisar os processos de produção de si e de realidade empreendidos por elas na Ala. Portanto, os critérios para serem entrevistadas eram: ser mulher, integrar a Ala e desejar participar.

Tanto a observação participante quanto as entrevistas iniciaram-se a partir da apresentação da pesquisa e de um convite a todas as mulheres na reunião geral da Ala. Para a realização das entrevistas também se utilizou uma mensagem-convite com nossos contatos, que foi enviada por Leci ao grupo que eles mantêm num aplicativo de troca de mensagens. Depois, enviamos outra mensagem-convite diretamente às mulheres que tinham maior frequência às reuniões de terça-feira. Construindo-se, pois, outro critério de inclusão nas entrevistas durante o processo mesmo da pesquisa: a maior presença no cotidiano da Ala. 


\section{Conversando com Jovelinas, Ivones, Beths...}

Quando a pesquisa se iniciou, a Ala reunia entre 80 e 100 membros, em sua grande maioria negros e distribuídos equilibradamente entre homens e mulheres. Considerando que é possível se licenciar da Ala a qualquer momento por motivos pessoais - o que implica uma diferença entre o número de membros inscritos e efetivos - e que há grande flutuação dos presentes nas atividades semanais, optamos, em negociação com eles, por utilizar nomes fictícios nas publicações referentes à pesquisa, bem como apresentar uma caracterização geral dos membros dos Cabelos Brancos, indicando seu perfil de composição e não elementos individualizados, que pudessem levar à quebra da confidencialidade pactuada. Vale ressaltar, ainda, que somente estivemos com quase todos os membros da Ala nas festas em que foram os anfitriões e no desfile no Sambódromo.

Os membros com que mantivemos mais contato, aproximadamente 35 dos mais assíduos, moram na região da grande Madureira e na Baixada Fluminense, pertencendo à classe trabalhadora. São ex-militares de baixa patente, professores, merendeiras, funcionários públicos, motoristas de ônibus, seguranças, costureiras, quituteiras, trabalhadores autônomos, terceirizados e do setor de serviços e comércio. Vários já se aposentaram, mas há aqueles que ainda trabalhem.

Observou-se que as formas como saúde e envelhecimento emergem nos discursos e práticas das mulheres dos Cabelos Brancos não se produzem num locus "blindado" à lógica hegemônica. Ao contrário, o anúncio de que se realizaria uma pesquisa sobre saúde e samba fez com que, num primeiro momento, as mulheres contassem de seus "prontuários médicos”. Surgiram episódios de câncer, cirurgias para colocação de prótese no joelho, depressão, acidentes vasculares cerebrais, hipertensão arterial e diabetes, ratificando as análises de morbidade para a velhice.

Contudo, tão logo terminavam de enumerar doenças mudavam de assunto e, entre um petisco e outro, uma cerveja e outra, começavam a narrar histórias de suas vidas, enfocando na maior parte das vezes relações familiares, afetivo-sexuais e de amizade e temas relativos ao trabalho e à violência urbana. Beth, por exemplo, tão logo nos apresentamos, contou que teve câncer de mama há alguns anos, mas que está "ótima”. Logo, emendou dizendo que era viúva e resolveu assumir o "namorido". O "papo" prosseguiu com ela narrando detalhes sobre os contratos de sua relação afetiva, o seu cotidiano com diversas atividades e o cuidar das netas.

Poder-se-ia argumentar que num espaço dedicado à festa seria evidente a ausência de temas relativos ao adoecer. Entretanto, não foi o que observamos. Nas conversas surgiram, por exemplo, comentários sobre o marido com colesterol e triglicerídeos altos e ter que "cozinhar a dieta dele" ou a convivência com o pai com Alzheimer, mas para falar da dupla/ tripla jornada de trabalho feminino e do peso do cuidar dos outros na vida. Ou sobre o agendamento da cirurgia da prótese de joelho somente para dizer que pela data, com fisioterapia e uma "dietinha", ia "dar para desfilar, se Deus quiser".

As práticas de autocuidado vinculadas à lógica da promoção da saúde também estiveram presentes nas conversas do "escritório". Porém, só quando éramos as interlocutoras privilegiadas, como se fosse esperado que desejássemos ouvir sobre o tema. Assim, algumas mulheres falaram sobre praticar natação, caminhada e hidroginástica, integrar grupos de atividade física e dança nas praças e/ou desenvolverem atividades no SESC. Nessas ocasiões, o argumento central do engajamento girava em torno de poder transgredir, arriscar-se. Tratava-se de investir no autocuidado para "tomar cerveja todos os dias", "desfilar no chão" e ir a festas e pagodes. 
A saúde emergiu como recurso para se fazer o desejado, mas não se apresentou como uma preocupação contínua nas conversas entre elas nem como aquilo que oriente a priori uma renúncia aos prazeres associados ao mundo do samba. Adotar as prescrições dos saberes médicos tinha uma perspectiva transitória e debochada, que envolvia garantir um "passe livre".

Assim, Ivone nos conta que a médica não "permitiria” que ela desfilasse no carnaval caso não emagrecesse nem se cuidasse. Então, quatro meses antes começou a dieta - "comer só alface, parei de beber e comecei na ginástica". Emagreceu quatro quilos, os exames comprovaram redução de glicemia e colesterol e, portanto, "consegui desfilar". Na sequência, ri e diz que incluiu o arroz integral, feito com cenoura e brócolis, em sua dieta, pois "alguma coisa que a doutora fala a gente tem que fazer. Pega mal não aproveitar nada que ela diz." No entanto, passado o carnaval, ela conta que parou com a dieta "bem certa mesmo". Segue fazendo alongamento, ginástica, dança do ventre e aula de consciência corporal numa instituição que as oferta gratuitamente, porém as atividades são uma ocupação para "conversar com pessoas diferentes" e "não ficar com os problemas em casa".

“Os problemas" e as maneiras de se relacionar com eles aparecem como elementos importantes para os sentidos de saúde acionados pelas mulheres dos Cabelos Brancos.

Eu tenho saúde porque eu consigo acordar e dormir com os meus problemas, sem que eles me maltratem, entendeu?... Saúde é viver um dia de cada vez, ser saudável é viver um dia de cada vez, é não se desesperar... (Pinah, mar./2019)

Você tem que se divertir, tem que se distrair. Não absorva problemas, nada, nada, nada da sua vida. Porque devido aos problemas você perde até a saúde ... A mulher é muito cobrada ... com filhos, casa, trabalho, mas ela tem que procurar alguma coisa para se divertir ... você se distraindo afasta um pouco a doença" (Alcione, mar./2019)

Tais problemas, embora possam incluir o processo saúde-doença, falam mais da situação econômica, da violência urbana, do mundo do trabalho e das relações. Problemas que são compartilhados e tratados no mundo do samba, pois "isto é vitamina, isto que me reergueu", "cura tudo", "não fico tão ranzinza".

Se compreendemos como afirma Vladimir Safatle (2015) que saúde "é um estado de equilíbrio dinâmico instável" (p. 344), em que o vivente se tor na sujeito pela capacidade de instituir normas que lhe sustentem a vida. Parece-nos que as mulheres da Ala produzem territórios existenciais que são atravessados pelos saberes médicos, mas estabelecem modos de viver em que os sentidos de saúde remetem a outros universos de referência.

Se quanto à saúde é possível encontrar pistas de outros caminhos para a produção de si e de realidade, também podemos percebê-las em relação à velhice. Embora as mulheres da Ala não ignorem a passagem do tempo, afinal são mulheres dos Cabelos Brancos, o envelhecimento não aparece nas conversas como uma preocupação em si.

Pode-se pensar que, se constituindo por mulheres entre 50 e mais de 80 anos de idade, seja a Ala um espaço propício para vermos funcionar uma atitude de resistência ao envelhecimento, como analisada por Guita Debert (1988) e sintetizada na expressão: "velho é sempre o outro" (p. 538). De fato, as mais jovens não se colocam no lugar de "velhas" e afirmam que integram a Ala por motivos específicos. No caso de Jovelina, é seu coração que envelheceu por uma doença cardíaca crônica: "apesar de não aparentar ... mas, assim, meu coração é um coração de uma mulher de 70 anos, não é um coração de uma mulher de 49" 
(nov./2018). Já para Mariene, que já acompanhava as atividades da Ala ao lado da mãe e esperou ter a idade mínima para fazer parte da mesma, o interesse é a relação intergeracional: "sempre gostei, eu gosto de ficar no meio dos mais velhos, [porque] as mais velhas, elas sempre te dão aula, te ensinam. A gente aprende muito com elas” (nov./2018). Ambas integram uma velha guarda, mas isso não implica a afirmação de si mesmas no território da velhice.

Entretanto, essa não parece ser a atitude mais pregnante na Ala. Numa das reuniões, enquanto o marido de Clara distribui remédios que "estavam sobrando", é possível escutar "ser velho é uma droga mesmo". Bem como noutras entrevistas emergem falas como: "eu estou velha", "quando eu ficar mais velha", "estou ficando mais velha", "quando vocêfica velha". Há, pois, um reconhecimento da velhice como território existencial. O que entendemos ser menos difícil do que sugere a literatura (Debert, 1988; Motta, 2006) na medida em que são acionados práticas e sentidos distintos dos hegemônicos.

A velhice não parece se fixar nas ideias de decadência e fragilidade, pois ela pode "ser uma droga", mas, ao mesmo tempo, é lugar de quem dá "aulas". Aulas de vida, nas palavras de Mariene, e aulas de samba e tradição, na atribuição mesma do título de velha guarda. Como diz a música de Dicró e Pongá (2002), tomada como hino pela Associação das Velhas Guardas do Rio de Janeiro: "a velha guarda é o samba em pessoa", "é a espinha dorsal do samba".

A produção de si e de realidade vinculada ao plano de imanência donde emerge o samba é marcada pelas maneiras como as sociedades negro-africanas valorizam a oralidade e a ancestralidade (Rifiotis, 2006), bem como pela história das redes de proteção, da luta pela liberdade e das estratégias de sobrevivência desenvolvidas pelas populações escravizadas no Brasil (Velloso, 1990).

Não à toa, falar de si nas reuniões, festas e/ou entrevistas implicava contar da linhagem, do vínculo da família com o mundo do samba "desde sempre", de pais e avós "fundadores", de filhos e netos envolvidos com as escolas de samba. Ao mesmo tempo, envolvia o orgulho de conhecer histórias e fofocas e, agora, ocuparem um lugar social reconhecido. Assim, Aracy nos mostra uma pasta cheia de diplomas, nos quais o Império Serrano atesta sua contribuição à escola, a homenageia e a torna sócia remida.

Noutra perspectiva, a velhice significa autonomia para dizer não a obrigações indesejadas, namorar, morar onde e com quem quiser, ir ao samba e voltar a hora que lhes convier. Contudo, essa atitude de valorização da liberdade, da capacidade de condução da própria vida, não aparece ligada à proposição de uma "terceira idade", à mimetização da juventude para aproveitar a vida. Trata-se mais de uma conquista pelo esforço empreendido em estudar, trabalhar, criar os filhos, se sustentar e não precisar mais se submeter ao machismo de pais e maridos.

Beth diz que cuida dos netos para que as filhas possam trabalhar, mas isso não significa que elas têm direito de se meter em sua relação com o "namorido". Nem que ela vai deixar de fazer suas coisas no samba e na religião. Leci concorda e conta que por isso decidiu ter um espaço para ela e o "namorido" longe da família, alugando um apartamento no centro da cidade do Rio de Janeiro. Sair de perto da família provocou reações nos filhos: “Como assim vai morar lá?" Mas, ela fala que sempre trabalhou muito, criou eles e que agora eles devem viver suas próprias vidas. Nas palavras de Pinah: "a gente descobre que precisa dessa liberdade na última gota, na essência dela. Ser livre de verdade, pra dizer não, não quero saber... dá teu jeito. Eu agora, tudo na minha vida ó... como é que eu tô soltinha...” (mar./2019) 
A velhice como tempo de maior liberdade também se apresentou nos discursos das mulheres pesquisadas por Debert (1988). Sua análise sublinha a importância de considerarmos as mudanças histórico-sociais quanto às relações de gênero e suas repercussões na construção da velhice das mulheres. Assim, ela afirma que as mulheres passam a negar o modelo de envelhecer expresso por avós e mães e são impelidas a estabelecer outras normas.

Embora as mulheres dos Cabelos Brancos expressem uma série de impasses quanto às relações de gênero machistas que vivenciaram e/ou viram as figuras maternas vivenciarem, não nos parece que ocorra uma ruptura total com o modo de envelhecer de mães e avós. No entanto, é preciso sublinhar que existem práticas, discursos e afetos muito heterogêneos nas relações de cada uma delas com suas mães/avós e no interior mesmo de cada relação.

Há mães que surgem como presenças marcantes e valorizadas, que lutavam pelas filhas, criavam possibilidades de ascensão social e as preparavam para tensionar e/ou romper com estruturas machistas, embora elas mesmas não o tivessem logrado. Assim, nos apresentam mães que acatavam a regra machista de não frequentar o samba - "não é lugar de mulher casada" ou afirmavam que "mulher tem que ficar calada mesmo". E, simultaneamente, incentivavam a estudar e trabalhar. Mães que ensinavam "pra gente fazer diferente" e sublinhavam que era fundamental ter autonomia financeira: "seu marido é o seu salário".

Apesar dos ensinamentos das mães indicarem certo privilégio do mundo do trabalho, quando o assunto é a família persistem aspectos relativos à sua centralidade na vida e ao papel da mulher na sua sustentação. Assim, surgem "avós babonas", que levam para passear, assumem o cotidiano para os pais trabalharem, compram presentes e cozinham, estabelecendo muitas pontes com a imagem clássica de amorosidade, cuidado e dedicação. Embora, evidentemente, se trate de avós que fixam limites a essas "responsabilidades", mandam no próprio tempo e dinheiro, caiam no samba, tenham festa todo domingo e espantem a família: "Gente! ... As velhinhas bebem, bebem, bebem e não fica ruim".

Por fim, outro elemento que gostaríamos de apontar sobre os modos de produção de si e de realidade que se apresentam na Ala dos Cabelos Brancos remete à relação entre liberdade e sexualidade. Alda Britto da Motta (2006) apresenta estudos em que mulheres de bairros populares identificam a velhice à liberdade, mas a associam ao desinteresse dos maridos, à ausência de ciúmes. Uma liberdade que é proporcional à perda de valor no mercado sexual. Contudo, não encontramos essa associação nas relações que se estabelecem no mundo do samba como vivido pelos Cabelos Brancos. A Ala e suas atividades são espaços cheios de paqueras, "namoridos", amantes, traições e ciumeiras.

Numa das noites no "escritório" a conversa girava em torno das relações afetivosexuais. Uma das mulheres contava que ao ser paquerada pelo "namorido" o esnobou, mas que "ainda bem" venceu os preconceitos quanto à altura do pretendente. "É um cara sexualmente ótimo, que me agrada e que me dá prazer". Emendando o assunto, outra dizia que não adianta ficar com "homem que acaba com a gente", contando com raiva do ex-namorado que a traiu depois de três anos com uma imperiana de outra ala e falando que, "tudo bem", pois se tornou "amante de um sujeito da mesma ala que a dele".

Todavia, as práticas e discursos no que se refere à sexualidade não se apresentam sem atravessamentos de certa moralidade hegemônica (ou seria reserva de mercado?). Assim, noutra ocasião, contavam que a festa das Velhas Guardas do domingo anterior estava "quente", "os homens de lá estavam dando em cima de qualquer mulher". Várias das presentes comentavam com certo orgulho de terem sido cantadas, para logo em seguida falarem que vigiam os homens da Ala a fim de que não façam esse tipo de coisa nem sejam alvo das 
cantadas femininas. Unânimes, disseram "homem que é da Ala que é casado será monitorado e reprimido em qualquer postura que seja ou indique traição em relação à esposa ou namorada." O sui generis é que a vigilância se organiza em rede de solidariedade, de modo que todas as mulheres da Ala se ocupam do controle moral dos "homens do samba".

No cenário dos Cabelos Brancos, a velhice parece, pois, se constituir como um mosaico heterogêneo em que forças de repetição e diferenciação se (re)configuram mutuamente, fazendo emergir enunciados e práticas que não aderem imediata nem automaticamente à ideia de que envelhecer é um infortúnio. Mas, nesse movimento, também não adotam como estratégia a busca pela imagem-objetivo "envelhecimento ativo/ terceira idade". Operando modos de produção de si e de realidade que acontecem entre a lógica hegemônica e as forças dos sistemas negro-africanos que sobreviveram à diáspora e à escravização, tornam visíveis e dizíveis outras maneiras de viver. Maneiras de viver que se constroem na afirmação da vida, pois no samba "a gente fica assim sorrindo [ ... ] a gente fica resistindo" (Cruz \& Sombrinha, 1997).

\section{Considerações finais}

Analisando o poder, Foucault afirma-o como correlações de forças que só existem em ato, que percorrem todos os pontos do socius e se atualizam nas relações. Nesse sentido, o poder não é homogêneo nem se vincula a um único método, mas opera incessantemente nas microlutas cotidianas, articulando e inventando aparelhos e instituições que permitam seu funcionamento contínuo (Foucault, 1988, 1999).

Articulado à lógica neoliberal, o poder investe em ordenar as probabilidades, o campo de possibilidades em que se inscrevem os comportamentos. Portanto, o seu exercício exige um outro, sobre quem investirá e que precisa se manter como sujeito da ação. Governar as pessoas é instigá-las a se tornarem empresárias de si mesmas, reduzindo a sua potência em estabelecer e sustentar modos de produção de si e de mundo singulares.

Entendemos que as relações de saber-poder hegemônicas atravessam todo o socius e, portanto, não é possível pensar que exista um topos fora delas. Contudo, se o sujeito é efeito de um jogo complexo e estratégico entre poder e aquilo que lhe escapa, aquilo que é da ordem da liberdade, então interessa-nos analisar que tecnologias de si permitirão construir modos de existir menos dominados.

Nessa direção, a cartografia dos modos de viver das mulheres da Ala dos Cabelos Brancos fala-nos de territórios existenciais que se produzem entre linhas de forças heterogêneas: aquelas próprias à lógica hegemônica e outras vinculadas ao universo de referência do mundo do samba. Mas que investem em sustentar processos de singularização da existência.

Os enunciados e práticas relativos aos modos de produção de si e de realidade operados por Jovelinas, Ivones e Beths afirmam a construção de territórios existenciais, em que os sentidos da saúde e do envelhecimento não se vinculam exclusivamente a uma atitude previdente e contábil. Além disso, falam da plasticidade necessária à própria vida ao articularem diferentes regimes de verdade, compondo uma velhice que não se fixa em nenhum dos lados da polaridade fragilidade/envelhecimento ativo, mas enuncia esse como um espaço-tempo marcado pela existência de "problemas" que existiam antes dele - relacionais, de trabalho e violência - e afetam a saúde. Saúde que mantém seu instável equilíbrio na 
priorização do investimento no coletivo e na festa. Bem como um espaço-tempo em que a liberdade é valorizada e exercida na busca pelo prazer, que pode ser encontrado nas relações afetivo-sexuais, familiares e de amizade e no reconhecimento da importância do seu lugar social como mais velha, como mais próxima dos ancestrais.

\section{Notas}

1 Todos os nomes utilizados no presente texto são fictícios, assegurando a confidencialidade.

\section{Referências}

Blass, Leila M. S. (2011). Velha Guarda de escolas de samba: concepções e paradoxos. In Anais do XI Congresso Luso Afro Brasileiro de Ciências Sociais. Salvador: UFBA. Recuperado de http:// docplayer.com.br/6123030-Velha-guarda-de-escolas-de-samba-concepcoes-e-paradoxos.html

Britto da Motta, Alda (2002). Envelhecimento e sentimento do corpo. In Maria Cecília S. Minayo \& Carlos E. A. Coimbra (Orgs.), Antropologia, saúde e envelhecimento (pp. 37-50). Fiocruz.

Britto da Motta, Alda (2006). "Chegando pra idade”. In Myriam M Lins de Barros (Org.), Velhice ou terceira idade? Estudos antropológicos sobre identidade, memória e política (pp. 223235). Ed. FGV.

Camarano, Ana A. (2006) Envelhecimento da população brasileira: Uma contribuição demográfica. In Elizabete V. Freitas et al. (Orgs.), Tratado de Geriatria e Gerontologia (2a ed., pp. 88-105). Guanabara Koogan.

Caponi, Sandra (2016). Viver e deixar morrer: biopolítica, risco e gestão das desigualdades. In Marcos Nalli \& Sônia R. V. Mansano (Orgs.), Michel Foucault: desdobramentos (pp. 229246). Autêntica.

Castiel, Luiz D., Guilam, Maria Cristina C. R., \& Ferreira, Marcos S. (2010). Correndo o risco. Uma introdução aos riscos em saúde. Ed. Fiocruz.

Clarke, Adele E., Mano, Laura, Fosket, Jennifer R., Fishman, Jennifer R., \& Shim, Janet K. (2010). Biomedicalization: technoscience, health and illness in the U.S. Duke University Press, 2010.

Cruz, Arlindo \& Sombrinha. (1997). Samba é nossa cara. Youtube, 20 dez. 2017. Recuperado de https://www.youtube.com/watch?v=jYT9lw6J9eU

Dardot, Pierre \& Laval, Christian (2016). A nova razão do mundo: ensaio sobre a sociedade neoliberal. Boitempo.

Davis, Angela (2016). Mulheres, raça e classe. Boitempo.

Debert, Guita G. (1988). Envelhecimento e representações sobre a velhice. In Anais do VI Encontro de Estudos Populacionais (pp. 537-556). Olinda: ABEP. Recuperado de http://www. abep.org.br/publicacoes/index.php/anais/article/view/451/437

Debert, Guita G. (1997). Envelhecimento e curso da vida. Estudos Feministas, Florianópolis, 5(1), 120-128 Recuperado de https://periodicos.ufsc.br/index.php/ref/article/view/12564 
Debert, Guita. G. (2013). Feminismo e velhice. Sinais sociais, RJ, 8(22), 15-38.

Dicró \& Pongá (2002). Velha guarda. In Dicró no Piscinão[CD]. Recuperado de http://velhaguardarj.blogspot.com/p/hino.html

Foucault, Michel (1988). História da Sexualidade I: a vontade de saber. Graal.

Foucault, Michel. (1999). Em defesa da sociedade: curso no Collège de France (1975-1976). Martins Fontes.

Guattari, Felix (1992). Caosmose. Ed. 34.

Lopes, Nei \& Simas, Luiz Antonio (2017). Dicionário da história social do samba. Civilização Brasileira.

Neilson, Brett (2019). Globalização e as biopolíticas do envelhecimento. In Guita G. Debert \& Mariana M. Pulhez (Orgs.), Desafios do cuidado: gênero, velhice e deficiência ( $2^{\mathrm{a}}$ ed., pp. 2959). Unicamp/IFCH.

OMS - Organização Mundial da Saúde. (1946). Constituição da Organização Mundial da Saúde. Recuperado de http://www.direitoshumanos.usp.br/index.php/OMS-Organiza\%C3\%A7\%C3\%A3o-Mundial-da-Sa\%C3\%BAde/constituicao-da-organizacao-mundial-da-saude-omswho.html

OMS/OPAS. (2005). Envelhecimento ativo: uma política de saúde. OPAS.

Rifiotis, Theophilos (2006). O ciclo vital completado: a dinâmica dos sistemas etários em sociedades negro-africanas. In Myriam M. Lins de Barros (Org.), Velhice ou terceira idade? Estudos antropológicos sobre identidade, memória e política (pp. 85-110). Ed. FGV.

Romagnoli, Roberta C. (2009). A cartografia e a relação pesquisa e vida. Psicologia É Sociedade, 21(2), 166-173.

Rougemont, Fernanda R. (2016). Viver mais e envelhecer menos: a "fonte da juventude" como projeto científico. Gramma.

Safatle, Vladimir (2015). Uma certa latitude: Georges Canguilhem, biopolítica e vida como errância. Scientiae Studia, SP, 13(2), 335-367.

Silva, Kátia (2013). Quem é o dono do samba? Discursos sobre legitimidade, tradição e fronteiras. Dissertação de Mestrado, Programa de Pós-graduação em Relações Étnico-raciais. Centro Federal de Educação Tecnológica Celso Suckow da Fonseca, Rio de Janeiro.

Sodré, Muniz (2019). O terreiro e a cidade. A forma social negro-brasileira. Mauad.

Sodré, Muniz (1998). Samba, o dono do corpo. RJ: Mauad, $2^{\text {a }}$. ed.

Tedesco, Silvia H. (2015). A ética da pesquisa e a perspectiva da cartografia: algumas considerações. Rev. Polis e Psique, 5(2), 32-47.

Valença, Rachel \& Valença, Suetônio (2017). Serra, serrinha, serrano: o império do samba. Record.

Velloso, Mônica P. (1990). As tias baianas tomam conta do pedaço - Espaço e identidade cultural no Rio de Janeiro. Estudos Históricos, Rio de Janeiro, 3(6), 207-228.

Werneck, Jurema P. (2007). O samba segundo as Ialodês: Mulheres negras e a cultura midiática. Tese de Doutorado, Programa de Pós-graduação em Comunicação, Universidade Federal do Rio de Janeiro, Rio de Janeiro.

Zorzanelli, Rafaela T. \& Cruz, Murilo G. A. (2018). O conceito de medicalização em Michel Foucault na década de 1970. Interface, Botucatu, 22(66), 721-731. Recuperado de http:/ / www.scielo.br/scielo.php?script=sci_arttext\&pid=S1414-32832018000300721\&lng=en\&nrm=iso 


\section{ADRIANA MIRANDA DE CASTRO \\ https://orcid.org/0000-0003-1190-5828}

Analista de gestão em saúde pública da Fundação Oswaldo Cruz, atuando como Coordenadora de Promoção da Saúde na Vice-Presidência de Ambiente, Atenção e Promoção da Saúde. É Doutora em Saúde Coletiva pela Fiocruz e Mestre em Psicologia pela Universidade Federal Fluminense.

Endereço: Av. Brasil 4365, Prédio da Cogeplan, térreo. Rio de Janeiro, RJ, Cep: $21040-900$.

E-mail: drikamcastro@gmail.com

\section{CLAUDIA BONAN \\ https://orcid.org/0000-0001-8695-6828}

Graduação em Medicina pela Faculdade de Ciências Médicas da Universidade do Estado do Rio de Janeiro (1981). Doutorado em Ciências Humanas pelo Instituto de Filosofia e Ciências Sociais UFRJ (2002). Pós-doutorado no Centre de recherche médecine, sciences, santé, santé mentale, société (CERMES3/CNRS) (2012). Professora do Programa de Pós-graduação em Saúde da Criança e da Mulher do Instituto Fernandes Figueira (Capes 5), Fundação Oswaldo Cruz (IFF/Fiocruz).

E-mail: cbonan@globo.com

\section{PAULA GAUDENZI}

https://orcid.org/0000-0003-4039-1088

Possui graduação em medicina pela Universidade do Estado do Rio de Janeiro (2005), mestrado em Saúde Pública pela Escola Nacional de Saúde Pública (2010) e doutorado em Saúde Coletiva pela Universidade do Estado do Rio de Janeiro (2014). Atualmente é professora e pesquisadora da Fundação Oswaldo Cruz.

E-mail: paula.gaudenzi@gmail.com

\begin{tabular}{|l|l|}
\hline \multirow{2}{*}{ Histórico } & $\begin{array}{l}\text { Sulbmissão: 03/12/2019 } \\
\text { Revisão: 18/02/2020 } \\
\text { Aceite: 08/05/2020 }\end{array}$ \\
\hline $\begin{array}{l}\text { Concepção: A.M.C.; C.B.; P.G. } \\
\text { Coleta de dados: AMC } \\
\text { dos autribuição }\end{array}$ & $\begin{array}{l}\text { Análise de dados: A.M.C.; C.B.; P.G. } \\
\text { Elaboração do manuscrito: A.M.C. } \\
\text { Revisões críticas de conteúdo intelectual importante: C.B.; P.G. } \\
\text { Aprovação final do manuscrito: A.M.C. }\end{array}$ \\
\hline $\begin{array}{l}\text { Aprovação, ética } \\
\text { e consentimento }\end{array}$ & $\begin{array}{l}\text { O estudo foi aprovado pelo CEP/IFF, Plataforma Brasil, CAAE } \\
n^{\circ} \text { 9002.1118.3000o.5269. }\end{array}$ \\
\hline Financiamento & Não houve financiamento. \\
\hline
\end{tabular}

